\title{
O design de livro-brinquedo: uma abordagem interacionista sobre ludicidade e desenvolvimento infantil
}

\author{
Toy book design: an interactionist approach \\ about playfulness and child development
}

livro-brinquedo, design gráfico, interação,

desenvolvimento infantil, ludicidade

toy book, graphic

design, interaction, child

development, playfulness
Artigo de revisão de literatura que aborda a ludicidade e o desenvolvimento infantil com base nas teorias interacionistas. Estudos na área neurocientífica e fisiológica confirmam que brincadeiras envolvendo formas simbólicas desenvolvem habilidades cognitivas e de linguagem, favorecem a compreensão, significação e a capacidade de solucionar problemas, além de trazer bem-estar emocional às crianças. Com foco no processo de design gráfico, este artigo tem como objetivo relacionar o aparecimento da dimensão simbólica e das habilidades cognitivas e as interações infantis com objetos singulares como os livros-brinquedo, especialmente no período de alfabetização. Relações estas que envolvem o estudo das representações do conhecimento, ou seja, a forma como as percepções ocorrem internamente, destacando a significação e a emoção durante o brincar. Esse estudo faz parte da pesquisa em andamento: "Desenvolvimento de heurísticas a partir da teoria dos affordances para o design de livro-brinquedo".

Literature review article that approaches playfulness and child development based on interactionist theories. Studies in neuroscientific and physiological fields confirm that activities that involve symbolic forms develop linguistic and cognitive abilities, encourage comprehension, significance and the capability of problem solution, besides bringing emotional wellness to the child. Focused on the graphic design process, this article aims to relate the appearance of the symbolic dimension and cognitive abilities with the child interactions with singular objects as toy books, especially in the literacy period. The relationships that involve the study of knowledge representations, that is, the way the perceptions occur internally, highlighting the significance and emotion during the play. This study is part of the research in progress: "Heuristics development based on the theory of affordances to toy book design".

\section{Introdução}

O brincar/jogar (play) é onipresente entre humanos de todas as sociedades, para Whitebread et al. (2012). Surge como um fenômeno multifacetado difícil de pesquisar pela espontaneidade e imprevisibilidade. As variações de tipos de brincadeiras parecem 
surgir de atitudes diferentes em relação à visão de infância e ao valor do brincar; aspectos como rigidez cultural, envolvimento de adultos, questões de gênero, espaciais (urbanas ou rurais), perigos circunstanciais, entre outros, interferem no brincar. Os autores atestam que há benefícios ao desenvolvimento infantil, sugerindo ser um consenso emergente quanto aos vários tipos de jogos e seus significados. Posição decorrente, em parte, do surgimento de evidências provenientes da psicologia evolucionária nas últimas décadas: à medida que cada vez mais animais complexos evoluíam, o tamanho de seus cérebros aumentava. Conforme os autores, esse aspecto pode ser associado a períodos cada vez mais longos de imaturidade biológica (período em que os jovens são cuidados pelos pais) e em paralelo ao aumento das brincadeiras.

Os livros-brinquedo são objetos lúdicos e interativos que convidam à experimentação. Têm uma narrativa aberta para diferentes leituras: visual (literária e imagética) e tátil (bi e tridimensional). Também pode conter recursos sonoros e olfativos, bem como efeitos de realidade aumentada ( $Q R$ code) entre outras tecnologias associadas. A obra "Pássaros e suas casas", de Walden e Robin (Figura 1), por exemplo, contém informações e imagens sobre como vivem os pássaros de forma lúdica. O texto narrativo convida o leitor a fazer as descobertas sob abas dispostas na ilustração, com recorte para facilitar o encaixe do dedo na aba. Além disso, a obra está constituída em formato de uma casa humana (estereótipo), buscando referenciar uma imagem padronizada, mas reconhecível para a criança. O papel firme do miolo e acabamentos como a capa dura e a superfície brilhante do papel favorecem o manuseio por crianças pequenas e bebês (em leituras mediadas).

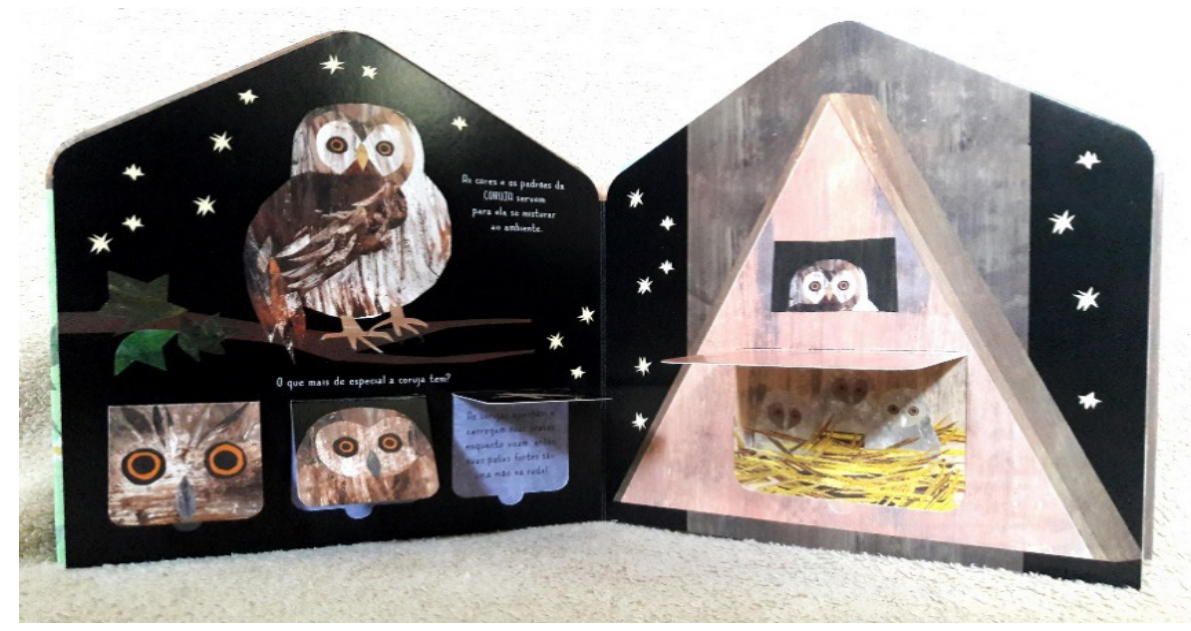

Figura 1 Livro-brinquedo "Pássaros e suas Casas", de Libby Walden, ilustrado por Clover Robin, e tradução de Márcia Duarte Campanhone, Barueri: Brasil Franchising SA, Tigertales, 2018. Fonte: acervo pessoal. 
Libros-brinquedo são objetos de formato mutante, em que a leitura se dá pelo manuseio, pela experimentação sempre diversa. Por essas características exploratórias, não se considera que haja desenvolvimento de um esquema mental por iteração, ou seja, como um treino por ações repetitivas. Porém, ao longo do tempo, a interação com esse tipo de artefato pode fornecer um tipo de "despertamento" para as propriedades e funcionalidades dos produtos contemporâneos, mas também para a associação entre imagens e memórias, favorecendo a experiência e a significação (Schmidt, 2017).

Esse estudo busca associar a ludicidade na infância a partir do design de objetos, para que o design de livro-brinquedo e outros objetos lúdicos possam estar em consonância com as teorias interacionistas, e o avanço das pesquisas sobre a cognição e a significação.

\section{Teorias interacionistas e o brincar}

Apoiado por pesquisas e observações de crianças, Piaget (1896-1980) desenvolveu as suas teorias de matriz interacionista. Ele afirma que "o conhecimento é construído durante as interações da criança com o mundo" (Seber, 2007, p.14). Esta interação é gradativa, assim como a organização das informações assimiladas. O final do período chamado por Piaget de "pré-operatório" (dois a seis anos de idade) marca o aparecimento da dimensão simbólica. É o momento em que a criança opera com a representação mental. Ao entrar no período "operatório concreto" (por volta dos sete anos de idade, fase de alfabetização), a criança já estará apta a operar mentalmente, e não mais apenas por representações. É capaz de atingir o pensamento lógico e efetuar trocas intelectuais, consolidar a comunicação e a socialização (Piaget, 2003; Seber, 2007).

As atividades multissensoriais como as brincadeiras permitem à criança formar novos repertórios de imagens mentais. Estas são representações mentais daquilo que não está sendo captado pelos cinco sentidos no momento (objetos, eventos, ambientes, reais ou imaginários). É mais comum nas imagens mentais preponderarem as imagens visuais que de outros sentidos (Sternberg, 2008). O uso de novas técnicas de pesquisa que incluem medidas neurocientíficas e fisiológicas, segundo Whitebread et al. (2012), mostraram relações consistentes entre o brincar das crianças e seu desenvolvimento cognitivo e emocional. A habituação infantil é a medida estabelecida pela rapidez com que uma criança processa informações, está relacionada com as habilidades cognitivas emergentes e possibilita uma previsão da quantidade de brincadeiras simbólicas que a criança praticará anos depois. Outras evidências apontam inter-relações entre as crianças que realizam brincadeiras simbólicas e seu bem-estar emocional, segundo os autores. 
Para Huizinga (2000), a ludicidade diz respeito a uma atividade voluntária humana, própria de qualquer manifestação cultural. O autor atesta que o brincar é natural aos humanos e aos animais, materializando um significado que ultrapassa a fisiologia: o divertimento causado pelas brincadeiras subsiste a qualquer justificação biológica, racional ou estética. Conforme Whitebread et al. (2012), os jogos entre humanos envolvem formas simbólicas que dependem das habilidades e da linguagem, como: usar expressões verbal e artística, dramatizar e jogar com regras. Estas ações concentram-se mais na significação, e seus participantes podem experimentar comportamentos exagerados, modificar, repetir ou alterar sequências, podendo oportunizar o desenvolvimento da capacidade de solução de problemas.

O desenvolvimento da linguagem (e outras formas de representação simbólica) é uma das habilidades da criança que brinca, e o desenvolvimento das habilidades de controlar seus próprios processos cognitivos e emocionais. O significado dessa percepção tornou-se cada vez mais reconhecido à medida que aumentava a evidência de que essas duas habilidades, linguagem e auto-regulação, estão intimamente relacionadas (Whitebread et al., 2012). Desta forma, conclui-se que a expressividade da criança é um importante meio de desenvolver-se.

A escola e a família são normalmente repressoras da expressão da criança, conduzindo-a para que ela "esteja dentro do tema" (Souza, 2003, p. 65). Nesse sentido a autora refaz o caminho do desejo de derivar da criança (de ouvir as palavras fora do assunto que elas expressam), e construir uma nova compreensão desse texto, que abarque o subtexto, deixando revelar-se como realidade própria e significativa a dimensão de valores emocionais, sociais, culturais, afetivos, acessando os modelos da ordem dominante. A consciência desperta pelo contato com o outro. Tais estudos apontam direções no sentido de relacionar as teorias interacionistas e as brincadeiras infantis.

\section{Interações cognitivas e a infância}

Os objetos do universo infantil são desenvolvidos, produzidos e comprados por adultos. É por suas percepções (de pais, professores, designers, editores, entre outros) que os objetos chegam às crianças, muitas vezes aliados ao ambiente educativo. Baseados em um senso comum acerca da infância e diante da oferta de produtos industriais, esses mediadores reiteram a ideia de que os objetos disponíveis são satisfatórios, inteligíveis, ergonomicamente adequados e comercialmente viáveis (Schmidt, 2017). Não obstante, avanços na área da ergonomia cognitiva e do design têm ampliado o estudo sobre a percepção do usuário rumo à revisão de conceitos estabelecidos a respeito da interação e da infância. 
Apesar dos estudos de anatomistas e neurologistas, a respeito das regiões do cérebro e suas faculdades correspondentes, Fialho (2001) defende que o pensamento ainda é um enigma. No entanto, para ele, quase todos os sentidos são viáveis à criança desde o nascimento. Como seres ativos frente às ansiedades, os bebês são biologicamente capacitados a experimentar a maioria das sensações através dos seus órgãos. Assim, a observação de crianças durante a brincadeira com objetos e a análise das ações e reações frente aos desafios perceptivos enfrentados podem gerar dados que trazem entendimentos valiosos para pesquisadores e designers, ainda que transitórios ou particulares de um sujeito.

Para Latour (2015), as concepções sobre as relações entre ações e o conhecimento têm se modificado em decorrência de pesquisas no campo das ciências cognitivas e outras áreas como sociologia das ciências e antropologia cognitiva, que localizaram essas ações em um mundo de objetos e, com isso, ampliaram o conceito de interação (antes reservado para relações entre seres vivos). Nas pesquisas, a interação é tratada em um recorte no espaço/tempo, com variáveis a serem avaliadas. Há críticas por parte dos opositores aos interacionistas, os estruturalistas, que consideram essa abordagem inconsistente. Entretanto, "a força da interação é justamente suspender local e momentaneamente as interferências. (...) A interação tem a forma contraditória de um quadro (que permite circunscrever) e de uma rede (que desloca a simultaneidade, a proximidade e a personalidade)" (Latour, 2015, pp. 167-168).

Como neurobiólogo, Maturana (2006) pesquisou a cognição humana a partir do sistema nervoso, sendo de principal interesse para ele os fenômenos da percepção em seus aspectos de captação, distinção e manuseio. $\mathrm{O}$ autor aponta, a partir de experimentos óticos cotidianos, que na interação com o mundo é necessária uma correlação interna. O sistema nervoso funciona desta forma: a correlação interna ocorre entre a atuação da retina e os sistemas motores, e não como a abordagem tradicional, entre corpo e objeto externo. Em nossa experiência humana, não se distingue a ilusão e o que chamamos de percepção e, diante disto, o autor constatou que é possível construir diferentes domínios de realidade. Estes domínios são legítimos porque são constituídos como "coerências operacionais explicativas do observador” (Maturana, 2006, p. 39).

De forma análoga, para Bouyer (2008), pesquisador no campo do trabalho humano, o operador (ou usuário de um sistema) não determina sua ação por uma representação mental que corresponda exatamente ao mundo exterior através da cognição. Aponta a percepção como orientadora da experiência, utilizando a expressão "mente incorporada" (Bouyer, 2008, p. 13), ou seja, o que se passa na interface é uma construção cognitiva única efetuada ou vivenciada por um agente também único. Para esse autor, ela não pode ser transmitida. 
A representação de conhecimento designa o conteúdo do que se sabe internamente sobre alguma coisa que está fora. Distingue-se: conhecimento representado em imagens mentais e conhecimento representado em formas simbólicas, como as verbais. A representação difere conforme a ideia, o assunto, e mesmo assim pode ser difícil comportar toda a ideia com uma imagem ou uma palavra. A representação contém atributos, mas é arbitrária, não é o mesmo que o real. Em suma: imagens informam concreta e espacialmente, em simultâneo, e palavras informam abstrata e categoricamente, em sequência (Sternberg, 2008). Estes dados informam sobre como o cérebro articula imagens mentais e ideias de caráter simbólico para que se formule uma compreensão de algo, material ou imaterial.

A linguagem escrita é realizada por sinais gráficos, arbitrários, das letras até o léxico que trata de registrar a história humana, as ciências, o pensamento, a literatura. A escrita invoca o som e o sentido que lhe foi designado, estabelecido pelo grupo social. A linguagem de sinais para surdos, por exemplo, que é totalmente visual, é utilizada nas deficiências auditivas e torna possível a comunicação inclusiva. Para os cientistas da cognição, as experiências visuais são importantes no processo perceptual, já que ocorrem antes da fala e fundamentam a nomeação das coisas e a representação mental, que Sternberg (2008) define como conjunto de informações que se tem sobre objetos e seres. No cérebro, as áreas que processam imagens não são as mesmas das que processam a fala, mas em conjunto com outras áreas especializadas interligadas formam a base da percepção (o aprendizado), e a base da cognição (o pensamento), conforme o autor. Essas abordagens são esclarecedoras para a compreensão de que o usuário de um sistema não é uma máquina operacional. São particularmente desafiadoras para o designer no seu trabalho de projetar sistemas mais confortáveis e humanizados para todos.

\section{A significação no design de produtos}

O que pode ser entendido por design envolve uma atividade de senso criativo, que admite como pontos principais: percepção, experiência e aparência. Por conseguinte, exercer ou vivenciar o design é promover sentido às coisas, conforme Krippendorff (2005). Essas descrições poderiam também denotar que produtos de design devem ser compreensíveis para seus usuários, e esta interpretação vai ainda mais ao encontro dos estudos do autor porque parecem romper com as tradições funcionalistas e caminhar em direção à significação. Ótica importante para uma pesquisa do campo do design que abrange objetos estimulantes de múltiplas leituras e brincadeiras como os livros-brinquedo e, portanto, aparecendo nesse tópico com muita ênfase.

$\mathrm{O}$ aperfeiçoamento dos parques gráficos, a partir de demandas de mercado no sentido da interatividade, e o crescimento de formação 
profissional na área do design gráfico têm resultado na publicação de inúmeras obras híbridas, ou seja, que mesclam em um único dispositivo editorial vários atributos e aplicações. Necessitando atender a dois ou mais conjuntos de funcionalidades, o designer deve assumir responsabilidades em relação ao desenvolvimento infantil que não são claras desde a sua formação. Agrava-se o fato desses projetos de produto serem destinados a estágios de maior variabilidade e exigência, em especial a fase de alfabetização, marcados por condições nas quais os produtos precisam estar de acordo com o corpo, percepção e cognição da criança, serem esteticamente agradáveis, e ainda produtiva e financeiramente viáveis (Schmidt, 2017).

Segundo Krippendorff (2005), os humanos não compreendem tudo o que acontece durante uma interação. O entendimento do usuário só pode ser observado pelo designer a partir das consequências dessa interação, que em geral envolvem a elaboração de modelos conceituais padronizados de comportamento. $\mathrm{O}$ designer só consegue compreender o que acontece na interação acessando os modelos conceituais do usuário, para assim responder como o raciocínio evoca a significação, como esta desdobra-se em ações, e como estas ações provocam o entendimento almejado, o comprometimento com a interação numa espécie de jogo.

Ao olharmos para os produtos que nos rodeiam, é possível perceber nesses objetos os códigos da cultura em que se inserem, ou seja, há um contexto semântico atuando que pode revelar uma circunstância histórico-cultural. Nessa lógica, projetar objetos da cultura é essencialmente trabalhar com a significação que resulte de interação pensada para seu usuário, em seu contexto, em uma forma adequada, que seja funcional, significativa e durável. Não há separação ou hierarquia entre os critérios de funcionalidade e significação (Souza, 2003).

Krippendorff (2005) desenvolveu uma teoria de sentido dos artefatos que questiona como os usuários compreendem seus objetos e relacionam-se com eles nos seus próprios termos de uso. É uma abordagem concernente à interação, abrange não só a cognição e a psicologia, mas também a natureza dos artefatos. Parte das perspectivas de outros autores pesquisadores do tema no curso da história (Norman, Wittgenstein, Gibson, Csikszentmihalyi, entre outros citados por ele), e amplia os conceitos vigentes, por referir-se ao envolvimento dos sentidos e ações dos corpos humanos em relação às superfícies, propriedades matéricas e formais dos objetos, reconhecendo o dinamismo da utilização de um produto, e da sua significação enquanto é usado.

O uso de um artefato se dá pelo encontro do usuário com o produto e a interface é o espaço de atuação próprio para ocorrer uma interação. Krippendorff (2005) aponta que as raízes do termo "interface" não abrangem apenas os sistemas operacionais (como se apresentam em monitores de dispositivos tecnológicos), mas podem incluir, como conceito, a relação entre um corpo e qualquer 
objeto, sendo aplicada dessa forma abrangente nesse artigo. Para o autor, o ser humano é capaz de ações sensoriomotoras e significações na experiência com um objeto, e este apresenta sua condição exterior, as características superficiais, propriedades materiais e os modos de agir sobre ele (abrir, cortar, puxar, ler, entre outros), sendo alguns imprevisíveis no momento do projeto. Pode ocorrer uma disrupção na interação por incompreensão, falta de cuidado ou dificuldades do usuário, que pode machucar-se no uso ou não conseguir realizar o que pretendia. Os designers precisam prevê-la, projetando artefatos significativos que garantam a atenção do usuário: no reconhecimento do que é e para que serve; na exploração ágil de como funciona, de como conseguir efeitos específicos; na confiança de manejo, uma fluidez de uso para que sua atenção se volte inteiramente aos resultados. De outra forma, os usuários podem sentir-se desencorajados e, por fim, não se envolverem com o artefato, ocasionando a ruptura na interação. Estes fatores da experiência colaboram na funcionalidade, mas também na significação (Krippendorff, 2005).

O simbólico no design tem uma dimensão social, já que os artefatos atendem às demandas sociais de comunicação, expressão, vínculos interpessoais, entre outras. Para Souza (2003), as forças que atuam sobre a vida humana desde a infância repercutem os sistemas ideológicos vigentes, interferindo mesmo nos níveis mais subjetivos e afetando as relações humanas entre si e entre humanos e objetos. A autora atesta que "sabemos que a criança vive sua relação com o mundo e com os outros de um modo extremamente criativo" (Souza, 2003, p.74). Refletindo sobre o período da alfabetização, a autora diz que a pluralidade, a polivocidade da expressão semiótica infantil deve ser o objetivo de uma educação que valorize expressões autônomas, livres da modelação hegemônica, dos códigos estereotipados do sistema. Portanto, o design também deve ser capaz de abarcar uma dimensão crítica. Essa dimensão está figurada no que é denotado do artefato como um todo, seja em seu conteúdo simbólico, seja nas fases de sua vida útil (da produção ao descarte).

\section{0 design de livros-brinquedo, objetos lúdicos}

O livro-brinquedo é projetado e publicado de forma que seja explorado através do manuseio. Objeto que pode auxiliar no processo de aquisição de conhecimentos, esquemas lógicos e na organização de elementos conceituais próprios da fase de transição dos sete anos de idade, quando ocorre a alfabetização. Combina linguagens como narrativa verbal, visual e tátil, podendo originar múltiplas leituras por manuseio. A ludicidade é um fator preponderante. Outros exemplos: obras com propostas de brincadeiras que envolvem objetos, livros pop-up, com abas, vazados, com partes desmontáveis, texturas, entre outros (Schmidt, 2017). 
A leitura é uma tarefa que não está determinada por alguém, nem mesmo o autor. Na assimilação deste exercício, são necessárias uma interpretação e uma significação durante a interação. Ao explorar um objeto como o livro-brinquedo, uma criança estará desenvolvendo pensamentos, emoções e ações - em busca de associações que orientem a experiência - baseados em suas vivências. Destaca-se que "o fato essencial de que convém partir é que nenhum conhecimento, mesmo perceptivo, constitui uma simples cópia do real, porque contém um processo de assimilação a estruturas anteriores" (Piaget, 2003, p. 13). Desta forma, a assimilação cognoscitiva desempenha um papel essencial na aprendizagem. Esta assimilação diz respeito a duas questões essenciais: à significação conferida durante a interação e aos esquemas de ação vinculados à percepção, seja em um livro a ser manuseado, seja em um trajeto ou ambiente a ser percorrido. "A inteligência sensoriomotora consiste em coordenar diretamente ações, sem passar pela representação ou pelo pensamento. A percepção só tem sentido ligada às ações" (Piaget, 2003, p. 16).

Para uma experiência positiva, conforme Oliveira (2013), os livros lúdicos com montagens especiais devem comportar o trabalho conjunto dos profissionais que podem ser: autor, editor, ilustrador, designer, engenheiro do papel e produtor gráfico, em formatos tradicionais ou inventivos, como é o caso dos castelos, palcos, tabuleiro de jogos, travesseiros, maletas, entre outros, tipos de livros-brinquedo relacionados por Ramos e Paiva (2014). As autoras acrescentam que uma parte desses livros assume estratégias informativas e outra parte, literárias. Os livros também têm apresentado modificações que tendem ao entretenimento pela exigência dos leitores em plena era digital. Portabilidade e volubilidade de interesses também são alguns aspectos dessa conjuntura.

O livro-brinquedo "Os pontos cardeais acrobatas", de Andrés Sandoval (Figura 2), trabalha com efeitos óticos conseguidos com o uso de óculos 3D, contidos na obra, e efeitos cromáticos de impressão. As imagens de mãos infantis representam a tradicional brincadeira "cama-de-gato", com barbantes, de forma que as ilustrações parecem caminhar sobre as linhas, numa atmosfera circense. O papel é firme (Artboard $300 \mathrm{~g} / \mathrm{m}^{2}$ ) para que o livro possa ser apoiado em uma superfície e assim seja capaz de sugerir a participação efetiva da criança leitora. As imagens parecem saltar da página. 


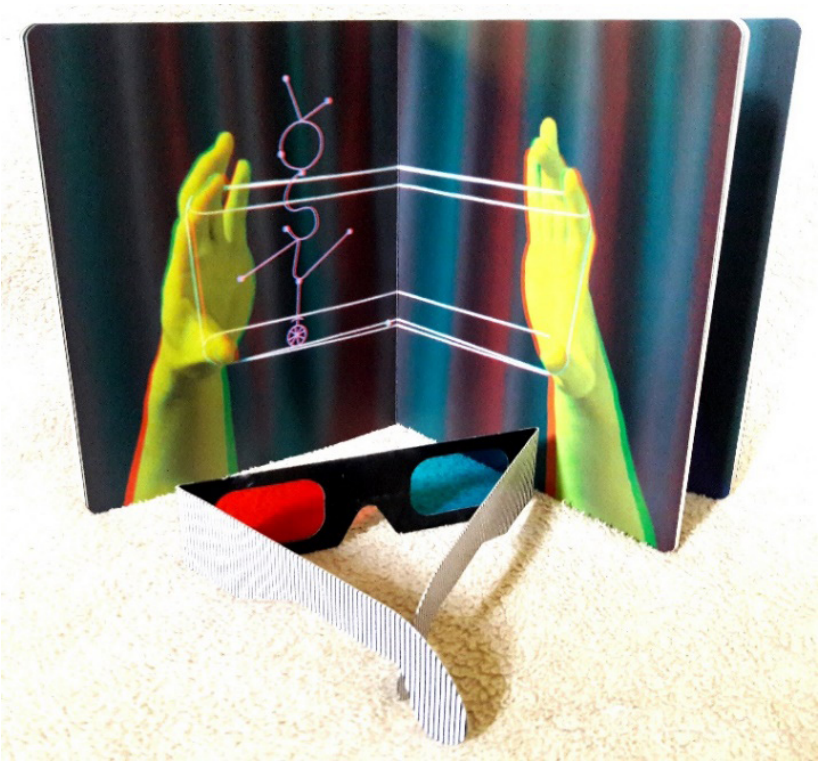

Figura 2 Livro-brinquedo "Os Pontos Cardeais Acrobatas", de Andrés Sandoval. São Paulo: Cosac Naify, 2013. Fonte: acervo pessoal.

Quando se trata do design de produtos, nenhuma interface é neutra, as interações despertam reações emocionais que podem ser mapeadas pelo designer. O campo interdisciplinar do Design Emocional começou a desenvolver-se a partir de uma conferência em 1999, em Delft, Holanda, onde foi criada a Sociedade Internacional de Design \& Emoção. Esse evento apenas formalizou um movimento que já fomentava a ideia de consumo de experiências e emoções transmitidas por produtos. É uma abordagem que amplia a concepção de produtos baseados só em habilidades físicas e cognitivas para outra mais abrangente, porque inclui o prazer aos fatores humanos. Essa perspectiva envolve o relacionamento de pessoas com objetos em um nível mais amplo, e o design como meio de valoração da vida diária. Não todo e qualquer projeto de design, mas aquele autoral, desafiador, satisfatório e relevante fonte de emoção. Os livros-brinquedo têm esse potencial. Os valores propostos pareceram intangíveis à época, mas aos poucos foram criadas ferramentas para apoiar o designer na tarefa de projetar com a consciência de fatores emocionais. Um exemplo de ferramenta é um instrumento de relato não verbal (por imagem), desenvolvido no ano de 1999 por Desmet para medir uma gama de 18 emoções positivas e negativas suscitadas pelo design do produto. Para projetar uma experiência emocional é preciso ao menos capturá-la ou monitorá-la na fase de avaliação do produto. Com a compreensão do designer de que a interação desperta emoção, ele poderá evitar respostas emocionais negativas inesperadas (Desmet; Hekkert, 2009). 


\section{Considerações finais}

Os livros-brinquedo são produtos híbridos (livro e brinquedo ao mesmo tempo), diversos entre si e pelas formas de manuseio, mas não são irreconhecíveis. São objetos culturais da produção editorial. Suas capas geralmente são como de outros livros, objeto de uso notório, com exceções de formatos arredondados, triangulares, entre outros mais exploratórios, como os livros-travesseiro. Ao abrir, percebe-se a presença do jogo no interior: não são páginas apenas para ver/ler, mas oferecem propostas lúdicas. Não há “tipos ideais” para interação nesse produto, embora se possa encontrar alguns padrões no mercado livreiro. Tende a ser inovador, mantendo a natureza experimental.

Sem o engajamento sensoriomotor do leitor, pode-se não compreender a narrativa, mas em particular, sem a conexão da narrativa com o jogo, conexão concebida por um designer, não se tem a experiência da significação proposta que só ocorre com uma leitura abrangente, não apenas como decodificação linguística. Assim, o projeto de livro-brinquedo não se limita em torná-lo atrativo e operacional, mas ele deve ter uma coerência forma-conteúdo para que sua dimensão simbólica seja exposta e percebida como jogo. De outra forma, será alcançada uma camada de significação diversa da potencialidade lúdica. Isso não pode ser julgado como inaptidão, a leitura desse objeto está sempre no limiar da imprevisibilidade.

De uma boa gestão de conhecimentos depende uma metodologia de design que considere os critérios estudados a respeito da infância em relação aos períodos de construção do conhecimento. As teorias interacionistas e as descobertas neurocientíficas mais recentes têm apontado a importância do brincar para a cognição, percepção e emoção da criança nas primeiras etapas da vida. As habilidades crescentes envolvem uma formação de repertório de imagens mentais que pode ser considerado nos projetos em relação a: interações, habilidades cognitivas e sensoriomotoras, linguagem, significação e emoção pela experiência com objetos.

Os autores estudados mencionam a representação mental como uma internalização do que foi captado pelos sentidos. Forma-se por iteração uma imagem mental arbitrária (em geral visual), que valerá para reconhecimentos posteriores. A entrada do período operatório marca o desenvolvimento da intelectualidade, na qual as representações mentais são acompanhadas de pensamento lógico. A representação mental difere da representação simbólica, que é uma das aquisições posteriores, a capacidade de perceber, analisar e compreender mais amplamente os símbolos. Nas experiências a partir dessa etapa de operações abstratas, na adolescência e fase adulta, alguns autores complementam essa ideia de combinação da ação com o pensamento lógico, em um conceito de "mente incorporada", sem passar pela representação mental, de forma que as decisões são tomadas por um conjunto de áreas distintas do cérebro durante a interação. Muitas pesquisas ainda precisam ser realizadas para a 
compreensão de como o cérebro funciona, as teorias abordam o tema dentro do paradigma científico vigente até ser ultrapassado por novas descobertas.

O reconhecimento de que as crianças têm uma forma criativa e aberta de perceber o mundo pelo seu brincar é uma maneira de aproximar-se delas, proporcionar-lhes a melhor experiência possível pelos objetos, sejam projetos de pequenos livros, sejam projetos ambientais dirigidos à infância. Cada período na construção do conhecimento oferece indícios de uma interação crescente em complexidade, em seus âmbitos variados, principalmente as habilidades cognitivas, semânticas, sensoriomotoras e emocionais. Neste ponto, destaca-se que as pesquisas teóricas e técnicas de observação são necessárias na análise científica e baseiam a práxis interdisciplinar do design. As etapas não serão corrompidas, uma vez que a construção é gradativa e não é possível apressar a criança no seu aprendizado. O que se pode fazer é conjugar elementos de interação lúdica, visando uma boa qualidade de experiência.

Pelo conhecimento teórico e suas relações contextuais, os designers e produtores de objetos para infância devem levar em conta questões de consumo e midiáticas que se apresentam massivas. O resultado deve ser responsável, já que crianças não deveriam ser consideradas consumidoras, do ponto de vista ético. Que não apenas atendam demandas mercadológicas, mas sejam motivados a aprimorar a relação humano-objeto rumo ao estímulo cognitivo, ao brincar, à experiência significativa, sensível e emocional.

\section{Agradecimento}

Agradecimento à CAPES pela bolsa de doutorado concedida à autora no período da pesquisa, importante para o desenvolvimento dos estudos. 


\section{Referências}

Bouyer, G. C. (2009). Contribuição da abordagem enactivo-incorporada da ação operatória na atividade de trabalho: ontologias da realidade nos sistemas complexos de operações. 2008. 230 f. Dissertação (Mestrado em Engenharia) - Escola Politécnica, Universidade de São Paulo, São Paulo. Disponível em: https://www.teses.usp.br/teses/disponiveis/3/3136/tde-26092008095830/publico/Tese_CORRIGIDA_8_Gilbert_C_Bouyer.pdf. Acesso em: 20 jan. 2019.

Desmet, P. M. A.; Hekkert, P. (2009). Special issue editorial: design \& emotion. International Journal of Design, Taipei City, v. 2, n.2, pp. 1-6. Disponível em: http://www.ijdesign.org/index.php/IJDesign/article/view/626/255. Acesso em: 25 jan. 2019

Fialho, F.A.P. (2001). Introdução às ciências da cognição. Florianópolis: Insular.

Friedmann, A. (2014). Linguagens e culturas infantis. São Paulo: Cortez.

Huizinga, J. (2000). Homo ludens. São Paulo: Perspectiva.

Krippendorff, K. (2005). The semantic turn: a new foundation for design. Boca Raton, FL: CRC Press Taylor \& Francis Group.

Latour, B. (2015). Uma sociologia sem objeto? observações sobre a interobjetividade. Revista-Valise, Porto Alegre, ano 5, v. 5, n. 10, p. 165189, dez. 2015. Disponível em: https://seer.ufrgs.br/RevistaValise/article/ view/61073. Acesso em: 18 jan. 2019

Maturana, H.R. (2006). Cognição, ciência e vida cotidiana. Organização e tradução: Cristina Magro; Victor Paredes. Belo Horizonte: Editora UFMG.

Oliveira, K.S. (2013). Design De livro-objeto Infantil: O Papel da Experimentação Gráfica e de Elementos Lúdicos e Interativos na Experiência de Leitura. In: CONGRESSO NACIONAL DE INICIAÇÃO CIENTÍFICA, 13., 2013, Campinas, SP. Anais eletrônicos [...]. Campinas, SP: Faculdade Anhanguera. v.1, p. 1-11. Disponível em: http://conic-semesp.org.br/anais/files/2013/ trabalho-1000015173.pdf. Acesso em: 19 nov. 2018

Paiva, A. P. M. de. (2010). A aventura do livro experimental. São Paulo: EDUSP: Autêntica.

Piaget, J. (2003). Biologia e conhecimento: ensaio sobre as relações entre as regulações orgânicas e os processos cognoscitivos. 4. ed. Petrópolis: Vozes.

Ramos, F.B.; Paiva, A.P.M. de. (2014). A Dimensão Não verbal no Livro Literário para Criança. Revista Contrapontos, Itajaí, SC, v. 14, n. 3, p. 425-447, set./ dez. Disponível em: https://siaiap32.univali.br/seer/index.php/rc/article/ view/5919/3671. Acesso em 30 nov. 2018.

Schmidt, M.C. (2017). A interface do livro-brinquedo: uma abordagem do processo projetual. 2017. 134 f. Dissertação (mestrado em design) - Programa de Pós Graduação em Design, do Centro de Artes, Universidade do Estado de Santa Catarina, Florianópolis.

Seber, M.G. (2007). Construção da inteligência pela criança. 5. ed. 4. São Paulo: Editora Scipione.

Souza, S.J. (2003). Infância e linguagem: Bakhtin, Vigotsky e Benjamin. 7. ed. Campinas, SP: Papirus Editora. (Coleção Magistério: Formação e Trabalho Pedagógico). 
Sternberg, R. (2008). Psicologia cognitiva. 4. ed. Porto Alegre: Artmed.

Vigotski, L.S. (2008). Pensamento e linguagem. 4. ed. São Paulo: Martins Fontes. Whitebread, D. et al. (2012).The importance of play: a report on the value of children's play with a series of policy recommendations. [S. 1.]: University of Cambridge, 56 p. Disponível em: http://www.csap.cam.ac.uk/media/ uploads/files/1/david-whitebread---importance-of-play-report.pdf. Acesso em: 30 nov. 2018.

\section{Sobre os autores}

\section{Márcia Cattoi Schmidt}

mcattoi@hotmail.com

Ms, (doutoranda) no Programa de Pós-graduação em

Design (PPGDesign) da Universidade do Estado de Santa Catarina

(UDESC), Brasil.

\section{Célio Teodorico dos Santos}

celio.teodorico@gmail.com

Prof. Dr. associado e professor permanente no Programa de Pósgraduação em Design (PPGDesign) da Universidade do Estado de Santa Catarina (UDESC), Brasil.

Artigo recebido em/Submission date 25/01/2021

Artigo aprovado em/Approvement date 08/05/2021 